\title{
Confined placental mosaicism of Duchenne muscular dystrophy: a case report
}

\author{
Max Winerdal ${ }^{1}$, Eini Westenius ${ }^{1,4}$, Michaela Granfors ${ }^{2,3}$, Maria Pettersson ${ }^{1,4}$ and Erik Iwarsson ${ }^{1,4^{*}}$ (i)
}

\begin{abstract}
Background: Small copy number variations confined to the placenta are extremely rare findings in chorionic villus sampling, nonetheless of great clinical importance. To the best of our knowledge, this is the first reported case of confined placental mosaicism for an intragenic Duchenne muscular dystrophy (DMD) gene deletion.

Case presentation: We describe a pregnant woman where confined placental mosaicism for an intragenic DMD deletion was detected. She was referred for a chorionic villus sampling due to an increased risk of trisomy 21 derived from combined first trimester screening. Rapid aneuploidy detection showed a male fetus with normal results for chromosomes 13, 18 and 21. A chromosomal microarray demonstrated a deletion of exons 61-62 in the DMD gene in approximately $50 \%$ of the cells. A follow-up analysis on amniotic cells showed a normal result for the DMD gene. Hence, confined placental mosaicism was confirmed.

Conclusions: We propose tissue specific fragile sites as a possible theoretical mechanism for the formation of submicroscopic copy number variations and highlight that the finding of DMD deletion mosaicism in a chorionic villus sample might be isolated to the placenta. Therefore, confirmation by amniocentesis is of crucial clinical importance to avoid misdiagnosis of the fetus.
\end{abstract}

Keywords: Mosaicism, Placenta, Chorionic villus sampling, Amniocentesis, Chromosome fragile site, Duchenne muscular dystrophy, DNA copy number variation, X chromosome, Prenatal diagnosis, Confined placental mosaicism

\section{Background}

Duchenne muscular dystrophy (DMD) with X-linked recessive inheritance is the most common myopathy in children and affects one in every 3500 boys. It is caused by mutations in the dystrophin gene located on the short arm of the X chromosome (Xp21). Two-thirds of DMD cases are caused by a large deletion of one or several exons in the $D M D$ gene. Duplications, single nucleotide variants (SNVs), smaller deletions or insertions, and splice site changes account for the remaining cases. In

*Correspondence: erik.iwarsson@ki.se

1 Department of Clinical Genetics, L4:03, Karolinska University Laboratory, Karolinska University Hospital, 17176 Stockholm, Sweden

Full list of author information is available at the end of the article one-third of the cases with DMD, the pathogenic variant occurs de novo.

Confined placental mosaicism (CPM) develops as a result of a postzygotic mutational event and is defined as the presence of a chromosome aberration in a mosaic form in the extra-embryonic tissue and absence in the fetal tissue. CPM is observed in approximately $2 \%$ of chorionic villi samples analyzed with conventional karyotyping [1-4]. Three studies evaluating CMA and the detection of mosaicism in prenatal samples estimated the prevalence of mosaicism to between 1.8 and $4.1 \%$, suggesting higher detection rates with CMA than conventional karyotyping [5-7].

When a chorionic villus sampling (CVS) indicates mosaicism, it is recommended to perform an amniocentesis (AC) to exclude a true fetal chromosome aberration. original author(s) and the source, provide a link to the Creative Commons licence, and indicate if changes were made. The images or other third party material in this article are included in the article's Creative Commons licence, unless indicated otherwise in a credit line to the material. If material is not included in the article's Creative Commons licence and your intended use is not permitted by statutory regulation or exceeds the permitted use, you will need to obtain permission directly from the copyright holder. To view a copy of this licence, visit http://creativecommons.org/licenses/by/4.0/. The Creative Commons Public Domain Dedication waiver (http://creativeco mmons.org/publicdomain/zero/1.0/) applies to the data made available in this article, unless otherwise stated in a credit line to the data. 
Even in the case of a normal amniocentesis, genetic counselling can be challenging due to the possible pregnancy complications CPM can cause. Placental dysfunction leading to intrauterine growth restriction and other complications, such as pregnancy loss, pre-term births and newborns small for gestational age have been reported [8-11]. The magnitude of clinical symptoms caused by CPM for a submicroscopic CNV depend on the timing of the mutational event, which cell lineages are affected, the phenotypical consequences of the aberration and the impact on selection and cell viability [11, 12]. CPM can involve different types of numerical and/ or structural chromosome aberrations, where autosomal trisomies are the most common abnormality $[1,2,13]$. There is a vast amount of data on CPM for aneuploidy and structural chromosome aberrations [3, 14], but very few cases of CPM for submicroscopic copy number variations $(\mathrm{CNV})<10 \mathrm{Mb}[5,7,15,16]$. To our knowledge, the largest study regarding CMA detecting mosaicism for submicroscopic CNVs in prenatal samples is so far by Lund et al. who identified 93 cases of mosaicism out of 2288 (4.1\%) prenatal CMAs on uncultured chorionic villi [7]. In their study, $18.3 \%$ of the mosaicism cases involved submicroscopic CNVs, they confirmed the possibility of true fetal mosaicism (TFM) of a submicroscopic CNV in three new cases and they found no statistically significant difference in the prevalence of CPM and TFM when comparing mosaicism involving CNVs and whole chromosomes. There are eight previous cases of CPM for a submicroscopic $\mathrm{CNV}$ on the $\mathrm{X}$ chromosome reported in the literature $[5,7,15]$. To the best of our knowledge, this is the first report of a case of CPM for a $D M D$ gene deletion.

\section{Case presentation}

Our patient, a 34-year-old pregnant woman, G3 P2, without any known medical or hereditary history went through a combined first trimester screening with a nuchal translucency of $2.5 \mathrm{~mm}$ and a risk assessment of $1: 4$ for trisomy 21 . As per local routine, when the risk is $\geq 1: 50$, our patient was offered a chorionic villus sampling (CVS), which was performed at gestational age (GA) $13+1$.

Rapid aneuploidy detection using quantitative fluorescence polymerase chain reaction (QF-PCR) with a panel of PCR primers specific to chromosomes 13, $18,21, \mathrm{X}$ and $\mathrm{Y}$ showed a normal result and confirmed that the fetus was male. Chromosomal microarray (CMA) using array comparative genomic hybridization (aCGH) demonstrated a deletion of exons 61-62 in the $D M D$ gene $(\mathrm{Xp} 21.2, \approx 84 \mathrm{~kb})$ in approximately $50 \%$ of the cells (Fig. 1a). Multiplex ligation-dependent probe amplification (MLPA) confirmed the DMD deletion and substantiated the mosaic pattern.

Due to male gender of the fetus, $\mathrm{X}$-linked recessive inheritance and the possibility of CPM, an amniocentesis (AC) was performed. CMA of DNA extracted from uncultured amniotic cells showed a normal result for chromosome $X$ (Fig. 1b), suggesting that the microdeletion had arisen during placentation and was confined in mosaic state to the placenta. No further genetic analysis was performed. The second trimester ultrasound scan and an extra ultrasound at 35 weeks of gestation turned out normal. A healthy baby boy was born at GA $40+6$, with a birth weight of $3535 \mathrm{~g}$ and normal routine checks and follow-up visits until the age of 4 months.

\section{Discussion and conclusion}

Awareness of the fact that a $D M D$ deletion mosaicism in a CVS might be isolated to the placenta is of great clinical importance. Such a finding requires confirmation by $\mathrm{AC}$ in order to avoid errors in the assessment of genetic status in the fetus. This will be even more important to acknowledge since some NIPT platforms performance are rapidly approaching that of CMA. This enables readily detection of submicroscopic CNVs, where false positive results due to CPM must be excluded. When mosaicism for a chromosome aberration has been identified in a CVS, a normal AC suggests CPM and a noncarrier status of the fetus. However, a low-level true fetal mosaicism (TFM) is difficult to fully exclude. Nonetheless, a study by Lund et al. [7] indicates that the risk for a symptomatic low-grade TFM should be very low when placental mosaicism is demonstrated and the AC turns out normal.

For the eight previously reported cases of CPM for a submicroscopic deletion on the $\mathrm{X}$ chromosome, there are three cases of FMR1 deletion, two cases of IL1RAPL1 deletion and three cases of STS deletion [5, 7, 15]. Notably, the $D M D$ gene is located proximally alongside the ILIRAPLI gene within the fragile site FRAXC [17]. Furthermore, the FMR1 gene is located in the fragile site FRAXA and the STS gene in FRAXB [18]. Thus, fragile sites prone to de novo mutations seem to emerge as hotspots for submicroscopic deletions confined to the placenta. Investigation of fragile sites has revealed increased susceptibility in preferentially large genes, genes with a late replication timing and a paucity of replication origins during replication stress $[19$, 20]. Intriguingly, the $D M D$ deletion in our sample lies in a transcription factor binding site, in an intersection region for early and late replication timing as seen by Repli-seq data [21]. There is indirect indication of genomic instability in small $(<3 \mathrm{Mb}) \mathrm{CNVs}$ in other chromosomes than the $\mathrm{X}$ chromosome as well [6]. The same $\mathrm{CNV}$ regions found in CPM are repeatedly found as constitutional (mainly de 


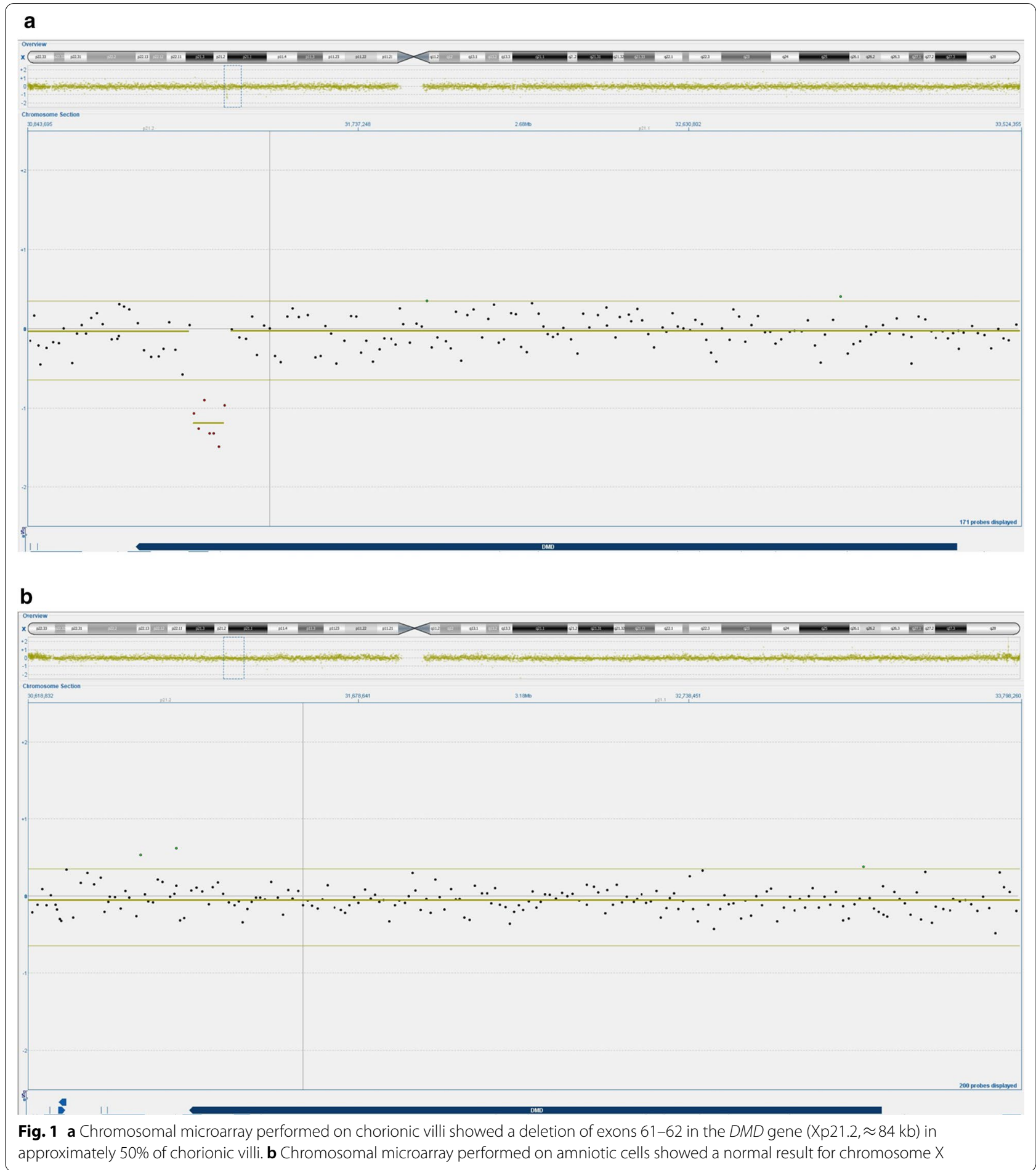

novo) mutations or as acquired mutations in cancers. Some CNV regions previously observed in CPM have, when constitutionally expressed, been reported to be susceptible to nonallelic homologous recombination [22], suggested as a fragile site [23] or as mutational hotspots [24, 25]. In contrast to other CNV regions found in CPM, subtelomeric rearrangements in the $9 \mathrm{q} 34.3$ region display nonrecurrent breakpoints [25]. Nonetheless, high rearrangement rates are seen in specific parts of this region, suggesting a different fragility mechanism. Furthermore, gender specific 
differences of rearrangement types have been observed in this region, which speculatively could be related to imprinting status. Since active transcription is a prerequisite for tissue type specific fragile site formation, only genes actively expressed in the tissue would be expected to be at increased risk for a submicroscopic deletion in placental tissue. CNVs in CPM larger than approximately $3 \mathrm{Mb}$ are more likely due to translocations or other chromosomal rearrangements, since other concomitant rearrangements or a sibling with chromosome aberration were observed to be present in those cases. Thus, there seems to be a multitude of mechanisms and different types of genetic regions involved in CPM, with genomic fragility as the unifying property. However, direct evidence of genomic fragility as a cause of CNV in CPM is still lacking and remains to be proven.

Although mosaicism for small CNVs confined to the placenta are extremely rare findings in CVS, misdiagnosis may occur unless a follow-up amniocentesis is performed.

\section{Abbreviations}

DMD: Duchenne muscular dystrophy; CVS: Chorionic villus sampling; SNV: Single nucleotide variant; CPM: Confined placental mosaicism; CNV: Copy number variation; GA: Gestational age; CMA: Chromosomal microarray; AC: Amniocentesis; DNA: Deoxyribonucleic acid; NIPT: Noninvasive prenatal testing; TFM: True fetal mosaicism.
\end{abstract}

\section{Acknowledgements}

Not applicable.

\section{Authors' contributions}

El supervised the work and obtained patient consent; MP, EW and El analyzed and interpreted the genetic analyses; MW and EW wrote the initial draft of the paper; MG performed the invasive tests and counselled the patient. All the authors contributed to and have approved the final version of the manuscript.

\section{Funding}

Open Access funding provided by Karolinska Institutet.

\section{Availability of data and materials}

All data generated or analyzed during this study are included in this published article.

\section{Ethics approval and consent to participate}

Written consent for participation and publication was signed by the patient. The study was approved by the Swedish Ethical Review Authority (reference number 2012-222-31-3).

\section{Consent for publication}

Written consent for participation and publication was signed by the patient.

\section{Competing interests}

The authors declare that they have no competing interests.

\section{Author details}

1 Department of Clinical Genetics, L4:03, Karolinska University Laboratory, Karolinska University Hospital, 17176 Stockholm, Sweden. ${ }^{2}$ Division of Obstetrics, Department of Women's Health, Karolinska University Hospital, Stockholm, Sweden. ${ }^{3}$ Clinical Epidemiology Division, Department of Medicine, Solna, Karolinska Institutet, Stockholm, Sweden. ${ }^{4}$ Department of Molecular Medicine and Surgery, Karolinska Institutet, Stockholm, Sweden.
Received: 9 September 2020 Accepted: 9 December 2020

Published online: 17 December 2020

\section{References}

1. Grati FR, Malvestiti F, Branca L, Agrati C, Maggi F, Simoni G. Chromosomal mosaicism in the fetoplacental unit best practice and research. Clin Obs Gynaecol. 2017;42:39-52.

2. Battaglia P, Baroncini A, Mattarozzi A, Baccolini I, Capucci A, Spada F, et al. Cytogenetic follow-up of chromosomal mosaicism detected in firsttrimester prenatal diagnosis. Prenat Diagn. 2014;34(8):739-47.

3. Malvestiti F, Agrati C, Grimi B, Pompilii E, Izzi C, Martinoni L, et al. Interpreting mosaicism in chorionic villi: results of a monocentric series of 1001 mosaics in chorionic villi with follow-up amniocentesis. Prenat Diagn. 2015;35(11):1117-27.

4. Hahnemann JM, Vejerslev LO. European collaborative research on mosaicism in CVS (EUCROMIC) — fetal and extrafetal cell lineages in 192 gestations with CVS mosaicism involving single autosomal trisomy. Am J Med Genet. 1997;70(2):179-87.

5. Gu S, Jernegan M, Van den Veyver IB, Peacock S, Smith J, Breman A. Chromosomal microarray analysis on uncultured chorionic villus sampling can be complicated by confined placental mosaicism for aneuploidy and microdeletions. Prenat Diagn. 2018;38(11):858-65.

6. Carey L, Scott F, Murphy K, et al. Prenatal diagnosis och chromosomal mosaicism in over 1600 cases using array comparative genomic hybridization as a first line test. Prenat Diagn. 2014;34(5):478-86.

7. Lund ICB, Becher N, Christensen R, Petersen OB, Steffensen EH, Vestergaard EM, et al. Prevalence of mosaicism in uncultured chorionic villus samples after chromosomal microarray and clinical outcome in pregnancies affected by confined placental mosaicism. Prenat Diagn. 2020;40:244-59.

8. Wilkins-Haug L, Quade B, Morton CC. Confined placental mocaisism as a risk factor among newborns with fetal growth restriction. Prena Diagn Publ Affil Int Soc Prenat Diagn. 2006;26(5):428-32.

9. Toutain J, Gouette-Gattat D, Horovitz J, Saura R. Confined placental mosaicism revisited: impact on pregnancy characteristics and outcome. PLoS ONE. 2018;13(4):e0195905.

10. Kalosek DK, Barett I. Confined placental mosaicism and stillbirth. Pediatr Pathol. 1994;14(1):151-9.

11. Robinsson WP, Barrett IJ, Bernard L, Telenius A, Bernasconi F, et al. Meiotic origin of trisomy in confined placental mosaicism is correlated with presence of fetal uniparental disomy, high levels of trisomy in trophoblast, and increased risk of fetal intrauterine growth restriction. Am J Hum Genet. 1997;60(4):917-27.

12. Biesecker $L G$, Spinner NB. A genomic view of mosaicism and human disease. Nat Rev Genet. 2013;15:307-20.

13. Hahnemann JM, Vejerslev LO. Accuracy of cytogenetic findings on chorionic villus sampling (CVS)_diagnostic consequences of CVS mosaicism and non-mosaic discrepancy in centres contributing to EUCROMIC. Prenat Diagn Publ Affil Int Soc Prenat Diagn. 1986;17(9):801-20.

14. Kalousek D, Vekemans M. Confined placental mosaicisim. J Med Genet. 1996;33:529-33.

15. Karampetsou E, Morrough D, Ballard T, Waters JJ, Lench N, Chitty LS. Confined placental mosaicism: implications for fetal chromosomal analysis using microarray comparative genomic hybridization. Prenat Diagn. 2014;34(1):98-101.

16. Oneda B, Baldinger R, Reissmann R, Reshetnikova I, Krejci P, Masood R, et al. High-resolution chromosomal microarrays in prenatal diagnosis significantly increase diagnostic power. Prenat Diagn. 2014;34(6):525-33.

17. McAvoy S, Ganapathiraju S, Perez DS, James CD, Smith DI. DMD and IL1RAPL1: two large adjacent genes localized within a common fragile site (FRAXC) have reduced expression in cultured brain tumors. Cytogenet Genome Res. 2007;119(3-4):196-203. 
18. Arlt MF, Miller DE, Beer DG, Glover TW. Molecular characterization of FRAXB and comparative common fragile site instability in cancer cells Genes Chromosomes Cancer. 2002;33(1):82-92.

19. Feng W, Chakraborty A. Fragility extraordinaire: unsolved mysteries of chromosome fragile sites. Adv Exp Med Biol. 2017;1042:489-526.

20. Glover TW, Wilson TE, Arlt MF. Fragile sites in cancer: more than meets the eye. Nat Rev Cancer. 2017:17:489-501.

21. Kent WJ, Sugnet CW, Furey TS, Roskin KM, Pringle TH, Zahler AM, et al. The human genome browser at UCSC. Genome Res. 2002;12(6):996-1006.

22. Mulle JG, Gambello MJ, Cook EH, et al. 3q29 Recurrent deletion. Sep 22 [Updated 2017 Oct 19] [ed.] Ardinger HH, Pagon RA, et al. Adam MP. Seattle (WA): s.n. (2016).

23. Burrow AA, Williams LE, Pierce LC, Wang YH. Over half of breakpoints in gene pairs involved in cancer-specific recurrent translocations are mapped to human chromosomal fragile sites. BMC Genom. 2009;10:59.
24. Unique. 8p23 deletion syndrome. Rarechromo.org. [Online] Version 2.1 (SW) 2013, 2013. https://www.rarechromo.org/media/information/ Chromosome\%20\%208/8p23\%20deletions\%20FTNW.pdf. Accessed 10 Oct 2020.

25. Yatsenko S, Brundage E, Roney E, et al. Molecular mechanisms for subtelomeric rearrangements associated with the $9 q 34.3$ microdeletion syndrome. Hum Mol Genet. 2009;18(11):1924-36.

\section{Publisher's Note}

Springer Nature remains neutral with regard to jurisdictional claims in publishedmaps and institutional affiliations.
Ready to submit your research? Choose BMC and benefit from:

- fast, convenient online submission

- thorough peer review by experienced researchers in your field

- rapid publication on acceptance

- support for research data, including large and complex data types

- gold Open Access which fosters wider collaboration and increased citations

- maximum visibility for your research: over $100 \mathrm{M}$ website views per year

At BMC, research is always in progress.

Learn more biomedcentral.com/submissions 